\title{
FOLKTALES AS MEANINGFUL CULTURAL AND LINGUISTIC RESOURCES TO IMPROVE STUDENTS' READING SKILLS
}

\author{
Ida Bagus Nyoman Mantra ${ }^{1}$, Dewa Gede Agung Gana Kumara ${ }^{1}$ \\ ${ }^{1}$ Universitas Mahasaraswati \\ e-mail: bagusmantra@unmas.ac.id, dewagana11@gmail.com
}

\begin{abstract}
Creating an English learning environment in which learners are highly motivated is sometimes very challenging for EFL teachers. Folktales can be useful for facilitating learners in their competence of English language and also for enhancing their cross-cultural awareness. In the field of language teaching, the richness and potential of folktales seems to have been under-utilized in today's language classes. This paper explores how folktales can be used as a medium of improving students' reading skills and major benefits in using folktales for teaching English. A classroom action research was employed to attain the purpose of this study in which two cyclic learning sessions were conducted to improve English learners' reading skills. Several selected Indonesian folktales were intensively utilized in reading classes. This result of this study indicates that use of folktales by EFL teachers could improve student' reading skill and widen their vocabulary and at the same time, culture is acquired by the students.
\end{abstract}

Keywords: Folktales. Culture, Improve, Reading skills

\section{INTRODUCTION}

Indonesia as an archipelago country has many islands and many ethnic groups who live together harmoniously. Indonesia has many folktales that have been passed on from generation to generation. This happened because folktales have important values for the community (Babalola, \& Onanuga, 2012). Folktales help the community to maximize their strengths in order to be able to live comfortable in cultural diversity. They become culture identity learned and shared by all members of the community (Cubitt, 2006). Folktales have the deeper meaning than most young generation can digest and they are often hard to comprehend without properly studying them thoroughly. Through folktales, people gain their cultural heritage which also determines their way of thinking, desires, behavior and attitudes as well their daily tradition (Ragan, 2009;
Mantra, 2017). Folktales make it easier for students to differentiate moral values, characters and impolite expressions. Moreover, folktales, to a great extent, help students develop their critical reading skills, fluency, and vocabulary and comprehension ability of particular events.

Folktales also develop students' ability in effective decision-making (Mantra, 2017). Characters in folktales consistently encounter conflicts which require higher skill in decision making to resolve a conflict. Consequently, folktales can demonstrate the importance of making appropriate decisions under challenging circumstances. Making students get involved in understanding folktales, it helps them to see the important of making appropriate decision although through difficult situation. The experiences that students learn from folktales helps them understand the importance of making effective 
decisions in their lives in order they are successful in living (Lwin, 2009; Mantra \& Maba, 2018).

In addition, folktales by their nature provide diversity (Mantra \& Maba, 2018). Through comprehending folktales, students are not only enhancing their linguistic ability but they also have the opportunity to discover valuable insights about their culture or other culture values, beliefs, history, practices and customs they have been celebrated within their community or other community. These really broaden their views of the world. They may also develop a greater appreciation of their own community and other community which bring them more tolerant to others (Mantra \&Widiastuti, 2018).

Using folktales in teaching English recently becomes more popular among language teachers (Mantra, \& Kumara, 2018). This is due the usefulness of folktales in enriching students' linguistic and cultural ability. As English becomes the language of the world, the intention to teach English more effectively becomes priority for all language teachers. In Indonesia in particular, English is the main subject to be taught in all formal schools. This occurrence is due to the phenomenon that English as a language of international communication among world community. Consequently English is learned more seriously by many people to attain a better prospect in the community of international world (Ragan, 2009).

English like many other languages consists of four skills (Mantra, \& Kumara, 2018). They are listening, reading, speaking and writing. Through reading, students can increase their knowledge many things. Moreover students can learn about new vocabulary, grammatical or tenses and generic structure of the text that can help them to improve their knowledge and improve their four skills. Reading is a complex activity that involves both perception and thought. One of the solutions to improve students' reading skill is by utilizing folktales (Mantra \& Maba, 2018; Westland, 1993).

Using folktales inthe reading classroom exposes students to distinctive opportunities for educational, intellectual, cultural and linguistic development (Ragan, 2009). Folktales are considered as one of the literary genres that can be used in the reading classroom to enhance language skill, motivate students, and increase their cultural awareness and to lerance (Mantra, \& Kumara, 2018). Folktales can be generated as apowerful and motivatingsource to make the students willing to read and practice English to develop their ability in vocabulary and grammar. Folktales are in a great extent, motivating and fun, they can help students develop positive attitudes towards the English language, willingness to read and may develop their extensive reading skill (Mantra, \& Kumara, 2018).

Engaging students to reading activity using folktales provides them with memorable experiences. Moreover, it also helps students learn how to make predictions, inferences and draw conclusions about actions, behaviors ofcharacters of the folktales (Mantra, \& Kumara, 2018). This ability may enrich their reading skill to the greater expense. This is because folktales are easy to read and they have practical length, which enables students to wrap up the discussion and analysis of the folktales in one learning session.

Many studies have been conducted concerning the use of folktales in the language classroom which revealed that folktales may increase students' language awareness, motivation ,personal reflection and cultural understanding. Unfortunately, little attention is given to folktales in the 
EFL reading classroom. In the light of the researchers' observations and experience in the field of English language teaching, insufficient number of language educators use folktales in their teaching practices. Some teachers refuse teaching reading using folktales because they believe that folktales may contain linguistic difficulty and cultural complexity. This study aims to demonstrate that folktales have the potential of enriching students' reading skills, enhancing their motivation in reading, and increasing their cultural sensitivity and awareness. Moreover folktales have their great capacity in increasing students' reading achievement.

\section{METHOD}

The subject of this study was a group of EFL students of English Study Program, Faculty of Teacher Training and Education, Mahasaraswati University in Denapasar. One class was chosen as the subject of the study. They were chosen as the subject of the study because their ability in reading comprehension as indicated by initial reflection was still very low. Therefore, immediate and appropriate teaching learning process needs to be carried out to solve the problem. This study was classroom action research (CAR) consisted of cyclical process in which in every cycle there were four interconnected activities such as: planning, action, observation, and reflection.

In the planning, the researcher prepared the instructional planning for each session before the present study was conducted in the classroom. In action, the researcher did teaching and learning process. Meanwhile, in the observation, the researcher carefully observed the learning activities. In this step, the researcher observed the subjects' attitudes and behavior toward teaching and learning process to see the improvement of the subjects. In reflection, the researcher analyzed the result of post-test and the result of observation.

The teaching and learning process were divided into two cycles. Each cycle consisted of two learning sessions which includes four interconnected activities. The four interconnected activities are planning, action, observation, and reflection. The results of reflection and observation from the first cycle were used to revise the planning for the second cycle.

\section{FINDINGS AND DISCUSSION}

In this classroom action research, data were collected by administering pretest, post-test and questionnaire. The aim of administering the pre-test was to examine the subjects' pre existing ability in reading comprehension before the treatment was given. Furthermore, the post- test was used in order to see the extent to which the strategy can improve the subjects' ability in reading comprehension.

\section{Pre-cycle}

In the pre-cycle, an initial reflection was conducted by doing interview to the English lecturers who taught reading comprehension at the selected class. The interview was intended to reveal how the students' learning and what strategies that are usually used in teaching reading, and then observation was also conducted. The interview indicated that the lecturers merely employed traditional method in teaching reading in which students were asked to read the reading texts for about 20 minutes and then followed by assigning the students to answer 5 questions presented below the text.

The aim of observation was to find out the real problems faced by the subjects. Based on the observation, the students found difficulty in reading comprehension 
especially in identifying general information, specific information, recognizing textual meaning and textual reference. These include various activities of reading comprehension to ensure students gain high comprehension of text.

Furthermore, a pre-test was carried out to know the pre-existing ability of the subject in reading comprehension before the teaching and learning process. The learning activities were started with the administration of pre-test in the form short answer questions consisting of 20 test items. The tests were constructed to measure students' reading comprehension, which were constructed to see the students' pre-existing ability in reading comprehension. The result of the pre-test showed that the students' reading comprehension was very poor, in which there were no subjects who could achieve the minimum passing grade. It showed that the subjects' reading comprehension needed urgently to be improved.

The mean figure of pre-test as an initial reflection was 4.60. This figure was considered to very low if it is compared with the minimum passing grade which has to be passed by the students, that is 7.50. Thus, to improve the subjects' reading comprehension, folktales were integrated in reading classes. The learning sessions were carried out in two cycles.

\section{Cycle 1}

The teaching cycle was carried out based on the result of the pre-test in which the score of the subject really below the standard minimum passing grade. Thus, an improvement action was planned through integrating folktales as an effort to improve students' reading comprehension. This cycle was divided in to 2 sessions. Each session consisted of four activities namely planning, action, observation, reflection.
The teaching sessions were prepared for 90 minutes for each session. For the first teaching session, the reading exercises for the first session were developed based on the story of The Black Hen, and the story of Cupak and Gerantang. Meanwhile, the exercises for second teaching session were designed based on the story of The Legend of Nyi Roro Kidul and the story of The Legend of Sangkuriang.

After designing the lesson plan, teaching action was carried out. In each teaching action, there were three main activities namely pre-activity, whilst activity, and post-activity. In pre-activity, the teacher arouses students' prior knowledge and link up the students' knowledge with the upcoming learning material. While-activity is the main activity of the learning process, meanwhile, postactivity is the concluding activity of learning. The main activity was started by asking the students to write down 10 statements expressing what they already knew about the story. They then asked to read them aloud. Prior to reading the text, students were asked to 10 questions that they wanted to know about the story.

Then, a post-test was administered in the post activity of the lesson in session 2. The subjects were asked to answer 20 questions related to the folktales being learned. The result of the post-test 1 showed that students' reading comprehension improved considerably.

In reflection, the researcher analyzed the result of post-test and the result of observation. and post activity. Based on the classroom observation, it showed that students were really active to participate in all learning activities. Additionally, the mean figure of post test result was 6.50. Based on the result of these sessions, it was decided to continue this study to the second cycle. 


\section{Cycle 2}

The second cycle was also conducted in four interconnected activities which were the same as the steps in first cycle, namely planning, action, observation and reflection. However there were some elaborations and revisions of the learning activity.

In planning, the lesson plan was revised from the lesson plan in the first cycle. The revision was made to make the second cycle more interesting for the subjects.

In the second cycle, students engaged in pairs and group learning activities. They were asked to seriously discuss their reading assignments in pairs and discussed them in groups. These types of activities enhanced students' reading skill more quickly as well as their social skill. The result of the classroom observation also indicated that students learning in pairs and in groups made the students really active in learning.

In addition, worksheet for the posttest was administered at the end of the second cycle. In this activity, the post-test was administered at the end of session 2 which consisted of 20 questions in the form of short answer task. The mean figure of the second teaching cycle was 8.40 . This indicated there was significant improvement achieved in post-test 2 as all students achieved the minimum passing grade. It meant that the use of folktales in reading comprehension was very effective. Moreover, the result of the questionnaire showed the responses of the subjects were positive.

\section{CONCLUSION}

Reading comprehension of the students in this study gradually improved through the integration of folktales in reading classroom. The use of folktales in English language classrooms can be a very practical and effective approach to teach language skills particularly reading comprehension, syntactical contents, diction, figurative meaning and cultural values. Therefore, it is highly suggested that language teachers utilize folktales as a valuable authentic resource of learning material to teach language and culture at the same time. Learning language by using folktales really challenges and motivates students to learn further and creating their awareness about their cultures and makes them aware out the existence of human beings whose have various characteristics, moral, thoughts, attitude and behavior. Through thorough understanding of their cultures that are being passed on from generation to generation, it enables them live more harmoniously in their society.

\section{REFERENCES}

Babalola, E. T. \& Onanuga, P. A. (2012).

Atrophization of minority languages: Indigenous folktales to the rescue. International Journal of Linguistics, 4(1), 158-173.

Cubitt, C. (2006). Folklore and historiography: Oral stories and the writing of Anglo-Saxon history. In E. M. Tyler, \& R. Balzaretti (Eds.), Narrative and history in the Early Medieval West (pp.189-224). Turnhout: Brepols Publishers.

Lwin, S. M. (2009). Revisiting a structural analysis of folktales: A means to an end? The Buckingham Journal of Language and Linguistics, 2(1), 6980.

Mantra, IBN. (2017). Promoting The Students'writing Skill Through Folktales Based Learning Activities. ISOLEC Proceeding. Faculty of Letters, Universitas Negeri Malang. 
Mantra, IBN ., Maba, W. (2018). Enhancing the EFI learners' speaking skill through folktales based instruction. SHS Web of Conferences 42, 00017.

Mantra, IBN ., Widiastuti, IAMS. (2018). Structural analysis and religiosity of Balinese song lyrics. International Journal of Linguistics, Literature and Culture 4 (4), 69-75.

Mantra, IBN ., Kumara, DGAG. (2018). Cyclic Learning Session of Indonesian Folktales Utilization To Improve Students'reading Comprehension. Media Bina IImiah 13 (1), 763.
Ragan, K. (2009). What happened to the heroines in folktales?: An analysis by gender of a multicultural sample of published folktales collected from storytellers. Marvels \& Tales, 23(2), 227-247.

Westland, E. (1993). Cinderella in the classroom: Children's responses to gender roles in fairy-tales. Gender and Education, 5(3), 237-249. 